\title{
2 年 \\ General pathways for obtainment of halo-containing 1,8- naphthyridines,1,8-naphthyridin-2(1H)-ones and their derivatives
}

\author{
Rosália Andrighetto (PG), Helio G. Bonacorso (PQ),* Felipe S. Stefanello (IC), \\ Marcos A. P. Martins (PQ), Nilo Zanatta (PQ) \\ Núcleo de Química de Heterociclos (NUQUIMHE), Departamento de Química, Universidade Federal de \\ Santa Maria, 97105-900, Santa Maria, RS. \\ *E-mail: heliogb@base.ufsm.br (H.G. Bonacorso)
}

Keywords: Trifluoromethyl group, 1,8-Naphthyridines, 1,8-Naphthyridin-2(1H)-ones

\section{INTRODUCTION}

The 1,8-naphthyridine core is a versatile template for drug discovery and deserves special attention because of their interesting complexation properties and medical uses. ${ }^{1,2}$ On the other hand, has been recognized that attachment of a trifluoromethyl group into heterocycles can be used to modulate the physical, chemical and biological properties. ${ }^{3}$ Furthermore, there are many chlorinated heterocycles that have important pharmacological activities such as example Clomacran, Chloroquine and Amodiaquine. In addition, reactions of chlorinated heterocycles with heteraromatic amines can attract specific interest to provide a synthetic route to aza-heterocycles. ${ }^{4}$ We have been engaged to establish protocols for regioselective cyclocondensation reactions of the type $C-C$ and / or $C-N$ from of a variety of $\beta$-alkoxyvinyl trifluoromethyl ketones (1) with 2,6-diaminopyridine (2,6-DAP) as well derivatization reactions from of the free amino group. $^{5}$

\section{RESULTS AND DISCUSSION}

1,8-Naphthyridines (4a-e) were obtained, instead of pyrimidines (3a-e), from direct cyclocondensation reactions employing 1a-e and 2,6-DAP. ${ }^{5}$ The compounds 2a-e when treated with $\mathrm{NaNO}_{2} / \mathrm{H}_{2} \mathrm{O}$ in $\mathrm{H}_{2} \mathrm{SO}_{4}$ or $\mathrm{HCl} / \mathrm{H}_{2} \mathrm{SO}_{4}(20 / 1, \mathrm{v} / \mathrm{v})$, at room temperature for 2 hours, furnished a new series of 1,8naphthyridin-2(1H)-ones (5a-e, $78-89 \%)$ or 7hydroxy-1,8-naphthyridines (6b-e, 78 - $86 \%$ ), respectively.

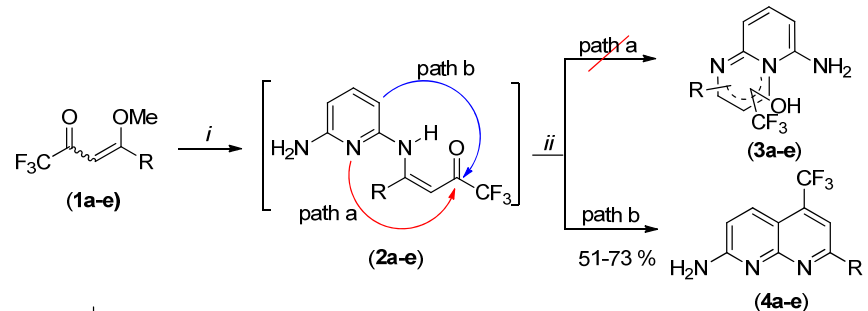

Posteriorly, the 1,8-naphthyridin-2(1H)-ones (5a-e) were treated with $\mathrm{POCl}_{3}$ at $110^{\circ} \mathrm{C}$ for 3 hours to give 2-chloro-1,8-naphthyridine derivatives (7a-e), in 74 $91 \%$ yields. The O-alkylation reaction of the compound $\mathbf{6 d}$ led to the derivative $\mathbf{8 d}$, in $82 \%$ yield (Scheme 1).

\section{CONCLUSION}

In summary, we have developed convenient, highly efficient and inexpensive routes for the preparation of a new series of compounds containing 1,8naphthyridine nucleous. Our strategy allows efficacy, rapidity and adequate diversity of substituents in the construction of the naphthyridine ring system. This process might lead to greater molecular diversity of trifluoromethyl substituted $\mathrm{N}$-heterocycles, which are of great potential interest for pharmacological and material applications.

\section{ACKNOWLEDGEMENTS}

CNPq, CAPES, FATECIENS

\section{REFERENCES}

${ }^{1}$ Repine, J. T.; Johnson, D. S.; Stuk, T.; White, A. D.; Stier, M. A.; Li, T.; Yang, Z.; Maiti, S. N. Tetrahedron Lett. 2007, 48, 8189.

${ }^{2}$ Jin, S. W.; Liu, B.; Chen, W. Z. Chin. Chem. Lett. 2007, 18, 383.

${ }^{3}$ Smart, B. E. J. Fluorine Chem. 2001, 109, 3.

${ }^{4}$ Manoj, M.; Prasad, K. J. R. ARKIVOC 2011, ix, 289.

${ }^{5}$ Bonacorso, H. G.; Andrighetto, R.; Krüger, N.; Zanatta, N.; Martins, M. A. P. Molecules 2011, 16, 2817.

\begin{tabular}{c|ccccc}
$1-9$ & a & b & c & d & e \\
\hline R & Ph & 4-MePh & 4-FPh & 4-BrPh 2-Thienyl
\end{tabular}

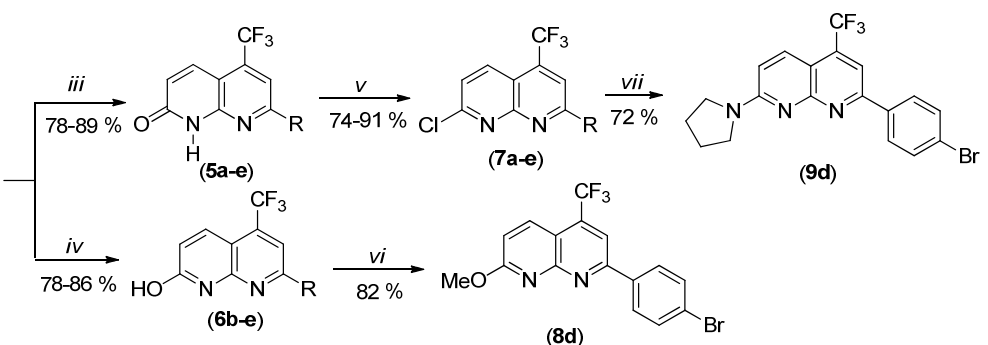

(i) = 2,6-Diaminopyridine, $\mathrm{MeOH}, 0^{\circ} \mathrm{C}, 2 \mathrm{~h} ; \quad$ (ii) $=\mathrm{MeOH}$, reflux, $24 \mathrm{~h} ; \quad$ (iii) $=\mathrm{NaNO}_{2}, \mathrm{H}_{2} \mathrm{O}, \mathrm{H}_{2} \mathrm{SO}_{4}, \mathrm{rt}, 2 \mathrm{~h} ; \quad$ (iv) $=\mathrm{NaNO}_{2}, \mathrm{H}_{2} \mathrm{O}, \mathrm{HCl}_{2} \mathrm{H}_{2} \mathrm{SO}_{4}(2 \mathrm{O} / 1), \mathrm{rt}, 2 \mathrm{~h} ; \quad(\mathrm{v})=\mathrm{POCl}_{3}, \mathrm{reflux}, 3 \mathrm{~h}$; (vi) $=\mathrm{CH}_{3}$ l, DMF, $40^{\circ} \mathrm{C}, 24 \mathrm{~h} ; \quad($ vii $)=$ Pyrrolidine, $120^{\circ} \mathrm{C}, 24 \mathrm{~h}$.

Scheme 1. 